\title{
Myocardial fibrosis in patients with myotonic dystrophy type 1: a cardiovascular magnetic resonance study
}

Helle Petri ${ }^{*}$, Kiril Aleksov Ahtarovski ${ }^{1}$, Niels Vejlstrup ${ }^{1}$, John Vissing ${ }^{2}$, Nanna Witting ${ }^{2}$, Lars Køber ${ }^{1}$ and Henning Bundgaard ${ }^{3}$

\begin{abstract}
Background: Myotonic dystrophy type 1 (DM1) is associated with increased cardiac morbidity and mortality. Therefore, assessment of cardiac involvement and risk stratification for sudden cardiac death is crucial. Nevertheless, optimal screening-procedures are not clearly defined. ECG, echocardiography and Holter-monitoring are useful but insufficient. Cardiovascular magnetic resonance (CMR) can provide additional information of which myocardial fibrosis may be relevant.

The purpose of this study was to describe the prevalence of myocardial fibrosis in patients with DM1 assessed by CMR, and the association between myocardial fibrosis and abnormal findings on ECG, Holter-monitoring and echocardiography.
\end{abstract}

Methods: We selected 30 unrelated patients with DM1: 18 patients (10 men, mean age 51 years) with, and 12 patients (7 men, mean age 41 years) without abnormal findings on ECG and Holter-monitoring.

Patients were evaluated with medical history, physical examination, ECG, Holter-monitoring, echocardiography and CMR.

Results: Myocardial fibrosis was found in 12/30 (40\%, 9 men). The presence of myocardial fibrosis was associated with the following CMR-parameters: increased left ventricular mass (median (range) $55 \mathrm{~g} / \mathrm{m}^{2}$ (43-83) vs. $46 \mathrm{~g} / \mathrm{m}^{2}$ (36-64), $p=0.02$ ), increased left atrial volume (median (range) $52 \mathrm{ml} / \mathrm{m}^{2}$ (36-87) vs. $46 \mathrm{ml} / \mathrm{m}^{2}$ (35-69), $\mathrm{p}=0.04$ ) and a trend toward lower LVEF (median (range) 63\% (38-71) vs. 66\% (60-80), $p=0.06)$. Overall, we found no association between the presence of myocardial fibrosis and abnormal findings on: ECG $(p=0.71)$, Holter-monitoring $(p=0.27)$ or echocardiographic measurements of left ventricular volumes, ejection fraction or global longitudinal strain $(p=0.18)$.

Conclusion: Patients with DM1 had a high prevalence of myocardial fibrosis which was not predicted by ECG, Holter-monitoring or echocardiography. CMR add additional information to current standard cardiac assessment and may prove to be a clinically valuable tool for risk stratification in DM1.

Keywords: Myotonic dystrophy, Cardiovascular magnetic resonance, Myocardial fibrosis, Risk stratification, Sudden cardiac death

\footnotetext{
* Correspondence: Hellepetri1@gmail.com

'Department of Cardiology, Copenhagen University Hospital, Rigshospitalet, Blegdamsvej 9, 2100 Copenhagen, Denmark

Full list of author information is available at the end of the article
} 


\section{Background}

Myotonic dystrophy type 1 (DM1) is an autosomal dominantly inherited neuromuscular disorder caused by an unstable expansion of a tri-nucleotide (CTG) repeat on chromosome 19 in the 3' untranslated region of the myotonic dystrophy protein kinase gene [1].

The cardiac phenotype of DM1 is complex and includes an increased risk of conduction disturbances, arrhythmias, compromised systolic and diastolic function and an approximately three-fold higher risk of sudden cardiac death (SCD) compared to age-matched healthy controls [2-4]. Additionally, disease progression is unpredictable, necessitating regular and repeated cardiac assessment and risk stratification for SCD $[3,4]$. According to Groh and co-authors, the presence of conduction disturbances, such as atrioventricular block (AVB) grade I and a clinical diagnosis of atrial tachyarrhythmia, are independent predictors of SCD [2]. Nevertheless, ECG, Holter and echocardiographic parameters are not sufficient for prediction of SCD.

Myocardial fibrosis has been identified in myocardial autopsies from patients with DM1 together with fat infiltration and myocyte hypertrophy and degeneration [5-7]. These findings are similar to observations in myocardial autopsies from other non-ischemic cardiomyopathies [5-8]. Myocardial fibrosis may not only explain the abnormalities in the cardiac conduction system but also work as a substrate for supraventricular and ventricular arrhythmias. Additionally, it may have a central role in the development of the systolic dysfunction observed in patients with DM1 $[2,7,9,10]$.

Cardiovascular magnetic resonance (CMR) is a wellestablished, non-invasive method to quantify heterogeneous myocardial fibrosis and assess left ventricular function and mass [11]. Screening procedures are needed for early detection of subclinical cardiac involvement in patients with DM1 and to identify those at high risk of SCD. CMR might become an essential screening-tool for identification of high-risk patients.

We investigated 30 unrelated and genetically verified DM1 patients with CMR and routine clinical screening to evaluate whether CMR add additional information about subclinical myocardial changes. In addition, our aim was to describe the prevalence and localization of myocardial fibrosis on CMR and to assess whether myocardial fibrosis was associated with abnormal findings on ECG, Holter-monitoring and echocardiography.

\section{Methods}

\section{Study design}

The study was conducted at the Departments of Cardiology and Neurology, Rigshospitalet, Copenhagen University Hospital, Rigshospitalet, Copenhagen, Denmark. We included a subgroup of patients $(n=30)$ from our cross-sectional study consisting of 129 genetically verified DM1 patients [4]. Except for CMR, methodology has previously been described in detail [4].

In brief, patients were evaluated with medical history, physical examination, 12-lead electrocardiogram (ECG), trans-thoracic echocardiography (including global longitudinal strain (GLS), 48-hour ECG-monitoring (Holtermonitoring) and CMR with late gadolinium enhancement (LGE). Blood samples were analyzed for plasma levels of NT-proBNP, myoglobin and creatine kinase (CK).

The study was approved by the regional scientific ethics committee (reference number H-d-2008-077) and all participating patients provided written informed consent.

\section{Study population}

A total of 30 patients were included for CMR; 18 patients (10 men, mean age 51 years) with, and 12 patients $(7$ men, mean age 41 years) without abnormal findings on ECG and Holter-monitoring. Patients matched the main cohort in regard to age, gender and cardiac involvement and none of the patients were related. Patients with contraindications for CMR e.g. respiratory assist devices and claustrophobia were excluded, and few patients declined participation due to severe muscular impairment.

The diagnosis of DM1 (based on CTG-repeat length) was confirmed either by Southern blot analysis and/or by TP-PCR $[1,12]$.

\section{Cardiovascular magnetic resonance}

CMR was performed using a 1.5 Tesla magnetic resonance scanner using a 6-channel body array coil (Avanto, Siemens, Erlangen, Germany). Balanced steady-state free precession end-tidal breath hold cine images were acquired in the two-, three-, and four-chamber views followed by contiguous short-axis plane slices covering the entire left ventricle $(\mathrm{LV})$ (echo time $1.5 \mathrm{~ms}$, resolution matrix $192 \times 192$, field of view $300-360 \mathrm{~mm}$, phases 25 , slice thickness $8 \mathrm{~mm}$ without interpolated gap) (Figure 1). LV volume measurements were performed by tracing endocardial borders in the short-axis stack images. Correct time

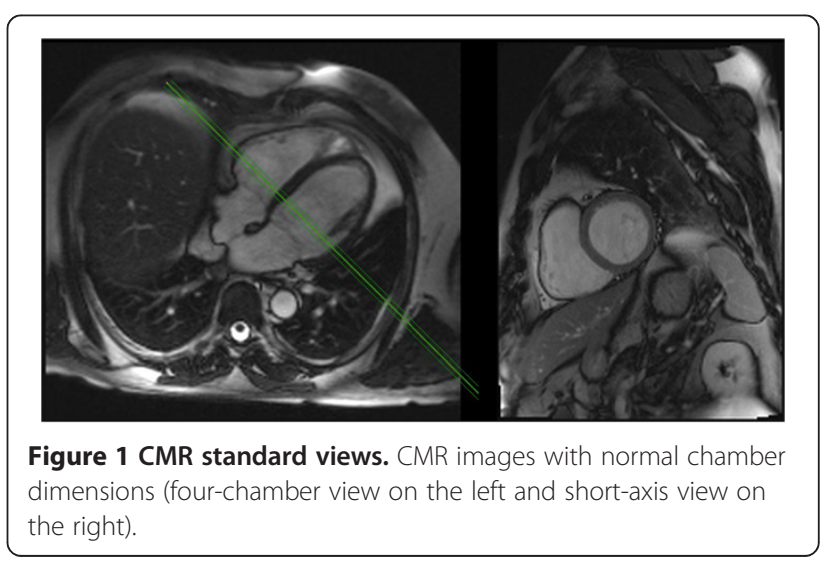


frames for LV end-diastolic volume (LVEDV) and LV end-systolic volume (LVESV) were automatically defined according to the size of the blood pool area, and LV ejection fraction (LVEF) was calculated accordingly. Papillary muscles were considered as part of the LV lumen. LV mass was measured at end-diastole by manually tracing the epicardial borders. To assess myocardial late gadolinium enhancement (LGE), we used T1-weightet inversion recovery gradient echo sequence (echo time $1.4 \mathrm{~ms}$, resolution matrix $192 \times 192$ and field of view, 300-360 mm). Images were obtained 10 minutes after intravenous bolus injection of $0.1 \mathrm{mmol} / \mathrm{kg}$ body weight gadolinium-diethylenetriamine pentaacetic acid (Gadovist, Bayer Schering, Berlin, Germany). The inversion time was continuously determined to null the signal from normal myocardium. Multiple $8 \mathrm{~mm}$ slices in the short-axis image plane were acquired to cover the entire LV without gaps. Myocardial fibrosis of the left ventricle was defined as hyper-enhanced myocardium with a signal intensity (SI) above 5 standard deviations from the SI in the normal myocardium. The extent of hyper-enhancement in each slice is determined and added up for total extent in grams by the software $\mathrm{cvi}^{42}$ (Circle Cardiovascular Imaging Inc., Calgary, Canada). All analyses were performed by an experienced CMR physician (KA). Furthermore, all LGE images were concomitantly analyzed and results agreed upon by two experienced CMR physicians (KA and NV); both blinded for other findings. The interobserver variation of LGE measurements has previously been described [13].

\section{Electrocardiography}

A 12-lead ECG was performed using a Burdick Atria 6100 ECG, Richmond, Australia. An abnormal ECG was defined as the presence of; atrial flutter/fibrillation (AFL/AF), atrioventricular block (AVB) grade I-III (AVB grade I: PR-interval $>220 \mathrm{~ms}$ ), right and left bundle branch block (RBBB/LBBB), QRS-interval >120 ms, incomplete right bundle branch block (IRBBB) and prolonged QTc $>450 \mathrm{~ms}$ in males and $>470 \mathrm{~ms}$ in females using Bazett's formula $(\mathrm{QTc}=\mathrm{QT} / \sqrt{\mathrm{RR}})$.

\section{Holter-monitoring}

A 48-hour Holter-monitoring was performed using a 3electrode Lifecard CF (Spacelabs Healthcare, Washington, United States). Holter-monitoring was considered abnormal in the presence of; AVB grade I-III, AF/AFL, other supraventricular tachyarrhythmia (SVT) ( $>30$ supraventricular premature contractions (SVPC) pr. hour or runs of $\geq 20 \mathrm{SVPC}$ ), frequent ventricular premature contractions (VPCs) $(\geq 30 / \mathrm{h})$ and non-sustained VT (NSVT) (minimum of 3 beats at $\geq 100 \mathrm{bpm}$ ).

\section{Transthoracic echocardiography and left ventricular longitudinal strain analysis}

Transthoracic echocardiography was performed using a Vivid e9 (General Electric, Horten, Norway). LV cavity dimensions, mass and wall thickness and diastolic dysfunction were assessed in accordance with the recommendations of the European Association of Echocardiography and the American Society of Echocardiography [14,15]. LV longitudinal function was assessed with global longitudinal strain (GLS) using a semiautomatic algorithm (Automated Function Imaging (AFI), GE), (normal reference GLS $\leq-15.9 \%$ ) [16].

An abnormal echocardiography was defined as left ventricular ejection fraction $\leq 50 \%$, left ventricular end diastolic diameter (LVEDD) $>53 \mathrm{~mm}$ (women) and $>59 \mathrm{~mm}$ (men), interventricular septum (IVS) $>11 \mathrm{~mm}$, left atrial volume indexed (LA vol.) $>34 \mathrm{ml} / \mathrm{m}^{2}$ and GLS $>-15.9 \%$. Additionally, echocardiography was used to assess valve disease and to estimate LV mass [14].

\section{Muscle strength analysis}

Muscle strength was graded using the Medical Research Council scale (MRC) $0-5 \quad(0=$ no ability to contract muscle, $5=$ normal strength). Early affection occurs primarily in the distal muscles in patients with DM1. Therefore, we investigated the association between handgrip (dominant hand) and ankle dorsal flexion and the presence of myocardial fibrosis on CMR.

\section{Statistics}

Data were analyzed with IBM SPSS Statistics version 19. Two sided p-values were calculated for all analyses; values $\leq 0.05$ were considered statistically significant. Normally distributed values are expressed as means \pm SD. Data with skewed distribution is given as median (range).

Categorical variables were summarized by frequency counts (percentage) and differences between groups were evaluated using chi-square test. Comparisons between categories were made with Mann-Whitney U test. Correlation analyses were performed using Spearman Correlation.

The patients included for CMR $(\mathrm{n}=30)$ were divided into two groups: one with $(n=18)$ and one without $(n=12)$ abnormal findings on ECG and Holter-monitoring to evaluate whether abnormal findings on conventional cardiac assessment were associated with fibrosis. Sample size calculation was based on the hypothesis that a minority of patients without abnormal findings on ECG and Holtermonitoring would have myocardial fibrosis (maximum prevalence 5\%). In contrast, we would expect myocardial fibrosis to be present in the majority of patients (app. prevalence 60\%) with abnormal findings on ECG and Holter-monitoring, corresponding to a total sample size of 28 patients with a power of $90 \%$, and a two-sided alphalevel of $5 \%$. 


\section{Results}

\section{Study population}

A total of 30 patients (17 men with a mean (SD) age of 47 (14) years) were included for CMR: 18 patients with, and 12 patients without abnormal findings on ECG and Holter-monitoring (Table 1). Patients with abnormal findings on ECG and/or Holter had higher NT-proBNP (Table 1). None complained of cardiac symptoms including palpitations, dizziness, chest pain, dyspnoea, peripheral oedema or syncope.

\section{Cardiovascular magnetic resonance}

Myocardial fibrosis of the left ventricle was found in 12/ 30 patients (40\%, 9 men) with a median LGE quantity of $4 \mathrm{~g}$ (range 1-17 g) (Figures 2 and 3). All patients were in sinus rhythm at time of the CMR. Gender specific CMR results are presented in Table 2 .

The presence of myocardial fibrosis, independently of quantity, was associated with the following CMR parameters: increased left ventricular mass, increased left atrial volume and a trend toward lower LVEF (Table 3). Two patients had reduced LVEF of $38 \%$ and $50 \%$ and concomitant myocardial fibrosis. Myocardial fibrosis did not correlate with age (Spearman correlation $\mathrm{r}=0.20, \mathrm{p}=$ $0.28)$.

Myocardial fibrosis was heterogeneously located in the left ventricle: anterior $(n=2)$, posterior $(n=1)$, anteriorseptal $(n=3)$, posterior-basal $(n=1)$ and lateral segments $(n=2)$. Of these nine patients, six had concomitant fibrosis of the anterior $(n=1)$, posterior $(n=4)$ and both hinge points $(n=1)$ between the right and left ventricle. Three patients had isolated prominent hinge point fibrosis, related to the anterior, posterior, and both hinge points, respectively. No fibrotic lesions were observed in the right ventricle.

\section{ECG}

With regard to the pre-selected DM1 subgroups, myocardial fibrosis was found in 8/18 (44\%) of the patients with abnormal findings on ECG and Holter-monitoring and interestingly in 4/12 (33\%) of the patients with normal findings on ECG and Holter $(\mathrm{p}=0.71)$.

Selected ECG, echocardiographic and Holter-monitoring results in patients with and without myocardial fibrosis are summarized in Table 3. Myocardial fibrosis was associated with IRBBB. There was no association between the presence of myocardial fibrosis and the following ECG parameters: AVB grade I, LBBB and prolonged QTc (Table 3). Overall, $7 / 30$ patients (23\%) had myocardial fibrosis and one or several abnormal findings on the ECG vs. 5/30 (17\%) patients with myocardial fibrosis and normal ECG ( $\mathrm{p}=0.71)$.

The quantity of LGE did not correlate with the following parameters: PR interval (Spearman correlation $r=$
$0.01, \mathrm{p}=0.97)$, QRS interval $(\mathrm{r}=0.23, \mathrm{p}=0.22)$ or QTcinterval $(\mathrm{r}=0.10, \mathrm{p}=0.59)$.

\section{Holter-monitoring}

The prevalence of abnormal findings on Holtermonitoring in patients with $(\mathrm{n}=12)$ and without fibrosis ( $\mathrm{n}=18)$ was: AF/AFL (3/12 vs. $1 / 18, \mathrm{p}=0.27)$, SVT (2/ 12 vs. $0 / 18, \mathrm{p}=0.15)$, AVB grade II $(0 / 12$ vs. $3 / 18, \mathrm{p}=$ $0.25)$, frequent VPC (2/12 vs. $2 / 18, \mathrm{p}=1.00)$, NSVT $(1 / 12$ vs. $0 / 18, \mathrm{p}=0.40)$. As reported, three patients (men, aged 46, 53 and 68 years) had paroxysmal atrial fibrillation and concomitant myocardial fibrosis, and one patient (a 46-year-old man) had permanent atrial fibrillation and flutter, which was terminated with radiofrequency ablation prior to CMR. Overall, no association was observed between myocardial fibrosis and abnormal findings on Holter-monitoring, i.e. 6/30 (20\%) had myocardial fibrosis and abnormal Holter-monitoring vs. 6/30 (20\%) with myocardial fibrosis and normal Holterfindings $(\mathrm{p}=0.27)$.

The quantity of LGE did not correlate with the number of VPC/h (Spearman correlation $\mathrm{r}=0.24, \mathrm{p}=0.20)$.

\section{Echocardiography}

When we added echocardiographic findings to the preselected DM1-subgroups, a total of $21 / 30$ patients had abnormal findings on ECG, Holter-monitoring and/or echocardiography, and of these 21 patients, myocardial fibrosis was present in 9 (43\%). Of the remaining 9 patients with normal routine cardiac screening 3 (33\%) had myocardial fibrosis. Taken together, no statistically significant association was observed between the presence of myocardial fibrosis and cardiac involvement on routine cardiac screening $(\mathrm{p}=0.70)$.

There was no overall association between abnormal findings on echocardiography and myocardial fibrosis on CMR, i.e. 4/30 (13\%) had myocardial fibrosis and abnormal echocardiography vs. 8/30 (27\%) with myocardial fibrosis and normal echocardiography $(\mathrm{p}=0.18)$. Furthermore, there was no association between myocardial fibrosis and the following specific echocardiographic parameters: LVEF $\leq 50 \%$ ( $2 / 12$ vs. $1 / 18, \mathrm{p}=0.55)$, IVSD $>11 \mathrm{~mm}(1 / 12$ vs. $1 / 18, \mathrm{p}=1.00)$, abnormal LVEDD (3/12 vs. $2 / 18$, $\mathrm{p}=0.36), \mathrm{LA}$ vol. $>34 \mathrm{ml} / \mathrm{m}^{2}(2 / 10$ vs. $0 / 18, \mathrm{p}=0.12)$ and abnormal GLS (3/10 vs. 2/16, $\mathrm{p}=0.34$ ).

The quantity of myocardial fibrosis correlated significantly with LA volume (Spearman correlation $r=0.40$, $\mathrm{p}=0.03$ ), but there was no correlation with the remaining echocardiographic parameters: IVSD $(\mathrm{r}=-0.10, \mathrm{p}=0.59)$, LVIDD $(r=0.25, p=0.18), \operatorname{LVEF}(r=-0.19, p=0.31), E / E^{\prime}$ $(\mathrm{r}=0.14, \mathrm{p}=0.50), \mathrm{E} / \mathrm{A}(\mathrm{r}=-0.05, \mathrm{p}=0.79)$, GLS $(\mathrm{r}=0.13$, $\mathrm{p}=0.54)$ and LV mass $(\mathrm{r}=0.05, \mathrm{p}=0.81)$. One patient (a 57-year-old man) had increased LV mass of $141 \mathrm{~g} / \mathrm{m}^{2}$ and concomitant myocardial fibrosis. 
Table 1 Clinical and cardiac findings in patients with DM1 prior to CMR

\begin{tabular}{llll}
\hline Demographics & $\begin{array}{l}\text { Patients without } \\
\text { abnormal findings } \\
\text { on ECG/Holter }\end{array}$ & $\begin{array}{l}\text { Patients with } \\
\text { abnormal findings } \\
\text { on ECG/Holter }\end{array}$ & p-value \\
\hline $\mathrm{N}$ & 12 & 18 & - \\
Gender & 7 men, 5 women & 10 men, 8 women & 1.00 \\
$\begin{array}{l}\text { Age (years), } \\
\text { mean (SD) }\end{array}$ & $41(10)$ & $51(15)$ & 0.05 \\
$\begin{array}{l}\text { Vital signs } \\
\text { SBP (mmHg), } \\
\text { mean (SD) }\end{array}$ & $115(11)$ & $126(19)$ & 0.09 \\
$\begin{array}{l}\text { DBP (mmHg), } \\
\text { mean (SD) }\end{array}$ & $74(10)$ & $76(11)$ & 0.64
\end{tabular}

mean (SD)

\section{Cardiac}

medications

$\begin{array}{ll}\text { B-blocker (n) } & 1 \\ \text { ACEI }(n) & 0 \\ \begin{array}{l}\text { Beta-blocker }+ \\ \text { ACEI }(n)\end{array} & 0\end{array}$

\section{Laboratory Data}

median (range)

median (range)

CK (U/l),

median (range)

$171(42-498)$

Muscle strength

testing

Handgrip (MRC),

median (range)

Ankle dorsal

flexion (MRC),

median (range)

\section{ECG}

PR interval (ms), median (range)

$179(130-200)$

QRS interval (ms),

median (range)

QTc interval (ms), median (range)

AVB grade I (n)

LBBB (n)

$88(70-110)$

$394(346-451)$

$\operatorname{IRBBB}(\mathrm{n})$

Holter-monitoring

AVB grade II (n)

AF/AFL (n)

SVT (n)

NSVT (n)

$\mathrm{VPC} / \mathrm{h}$,

median (range)
$240(160-260)$

0.006

$96(78-160)$

0.24

1.1 .00

$3 \quad 0.24$

$1 \quad 1.00$

$13(1-41) \quad 0.02$

$103(44-258) \quad 0.22$

$182(71-780) \quad 0.43$

$4.0(1-5) \quad 0.59$

$4.5(1-5) \quad 0.45$

$417(360-516) \quad 0.06$

$10 \quad 0.002$

$1 \quad 1.00$

$\begin{array}{ll}4 & 0.13\end{array}$

$3 \quad 0.25$

$4 \quad 0.13$

$2 \quad 0.50$

$1 \quad 1.00$

$4(0-421) \quad 0.004$
Table 1 Clinical and cardiac findings in patients with DM1 prior to CMR (Continued)

\begin{tabular}{llll}
\hline Echocardiography & & \\
$\begin{array}{l}\text { LVEF (\%), } \\
\text { median (range) }\end{array}$ & $57(48-67)$ & $58(45-67)$ & 0.72 \\
$\begin{array}{l}\text { IVS (mm), } \\
\text { median (range) }\end{array}$ & $8(6-13)$ & $8(5-11)$ & 0.87 \\
$\begin{array}{l}\text { LVEDD (mm), } \\
\text { median (range) }\end{array}$ & $46(40-60)$ & $47(41-56)$ & 0.97 \\
$\begin{array}{l}\text { LVPW (mm), } \\
\text { median (range) }\end{array}$ & $7(6-12)$ & $8(5-11)$ & 0.70 \\
$\begin{array}{l}\left.\text { LV mass (g/m }{ }^{2}\right), \\
\text { median (range) }\end{array}$ & $70(49-90)$ & $70(46-141)$ & 0.90 \\
$\begin{array}{l}\text { LA vol. (ml/m²), } \\
\text { median (range) }\end{array}$ & $22(14-36)$ & $25(17-38)$ & 0.50 \\
$\begin{array}{l}\text { GLS avg. (\%), } \\
\text { median (range) }\end{array}$ & $-19(-14$ to -23) & $-18(-14$ to -25) & 0.66 \\
\hline
\end{tabular}

ACEl: angiotensin converting enzyme inhibitor.

AF/AFL: atrial fibrillation/flutter.

AVB: atrioventricular block.

B-blocker: beta-blocker.

CK: creatine kinase.

DBP: diastolic blood pressure.

GLS: global longitudinal strain.

IRBBB: incomplete right bundle branch block.

IVS: interventricular septum.

LA vol.: left atrial volume.

LBBB: left bundle branch block.

LVEDD: left ventricular end diastolic diameter in diastole.

LVEF: left ventricular ejection fraction.

LV mass: left ventricular mass.

LVPW: left ventricular posterior wall.

MRC: medical research council scale.

NSVT: non-sustained ventricular tachycardia.

SVT: supraventricular tachycardia.

SBP: systolic blood pressure

VPC/h: ventricular premature contractions/hour.

Two patients with fibrosis had increased LA volume (36 and $38 \mathrm{ml} / \mathrm{m}^{2}$, respectively) but no other signs of diastolic dysfunction. Echocardiography excluded significant valve disease.

\section{Discussion}

This study demonstrates that adult patients with DM1 have a high prevalence of myocardial fibrosis (40\%). Myocardial fibrosis was associated with increased left ventricular mass, increased LA volume and a trend toward lower LVEF assessed by CMR. On standard cardiac screening, myocardial fibrosis was associated with IRBBB and correlated with LA volume assessed by echocardiography. Nevertheless, a normal ECG, echocardio-graphy and/or Holter-monitoring could not rule out the presence of myocardial fibrosis on CMR.

Physicians treating and referring patients with DM1 face a major challenge in handling the risk of SCD in these patients. Risk predictors for SCD in patients with DM1 are needed and specific ECG abnormalities, such as atrial tachyarrhythmia and $\mathrm{AVB}$, are already known predictors of SCD [2]. Studies have reported a correlation between 

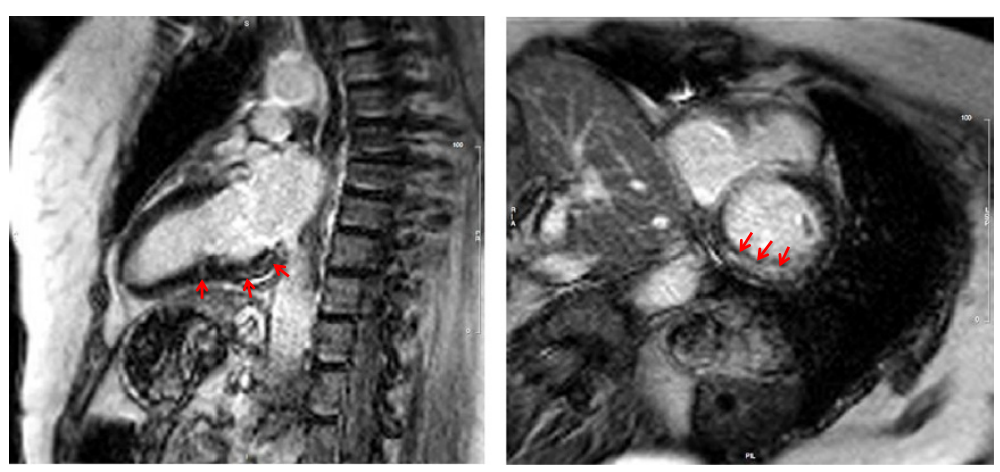

Figure $\mathbf{2}$ Late gadolinium enhancement. Representative images (long-axis on the left and short-axis on the right) of late gadolinium enhancement (marked with red arrows) in a 63-year-old woman with concomitant atrioventricular block grade I and frequent ventricular premature contractions on Holter-monitoring.

QRS-interval and myocardial fibrosis and an overall association between ECG abnormalities and abnormal CMR findings in DM1 patients [17-19]. Nevertheless, myocardial fibrosis in DM1 patients has only been investigated in few studies [17-21]. Although these studies are not directly comparable due to different CMR-techniques, myocardial fibrosis has been reported with prevalence ranging from 10 to $40 \%$, i.e. in the order of magnitude as presently found. Our study is the first to evaluate the association between myocardial fibrosis on CMR and a systematic standard cardiac screening including ECG, Holter-monitoring and echocardiography. A recent CMRstudy including 80 patients with DM1 reported myocardial fibrosis in 10 patients (13\%) and 9/10 had concomitant abnormal ECG [18]. In comparison, we found a higher prevalence of patients with myocardial fibrosis (40\%) and no association between myocardial fibrosis and abnormal ECG findings. The above findings substantiate that myocardial fibrosis has an impact on the pathogenic process of DM1, although not necessarily related to the findings based on routine cardiac evaluation [17-21].
In several cardiomyopathies, myocardial fibrosis seems to act as a substrate for ventricular arrhythmias. Furthermore, myocardial fibrosis is a dominant finding in endomyocardial biopsies from patients with spontaneous ventricular fibrillation and no other macroscopic cardiac disease [22-26]. Additionally, studies have demonstrated an association between the quantity of myocardial fibrosis and the risk of ventricular arrhythmias [27-30]. In patients with DM1, myocardial fibrosis has been observed in autopsy findings and in pathology studies with animalmodels of DM1 [6-8,31-35], giving evidence of a possible link between myocardial fibrosis and ventricular arrhythmias, which may lead to SCD. Skeletal muscle biopsies have also revealed fibrotic changes together with muscle fiber diameter variation, adipose deposition and a high number of central nuclei [36]. So far, there is no definitive pathogenic explanation for these histopathological alterations, although combined effects of misregulated splicing of several genes involved in calcium regulation and extracellular coupling may contribute to the muscle degeneration $[37,38]$. Nonetheless, myocardial
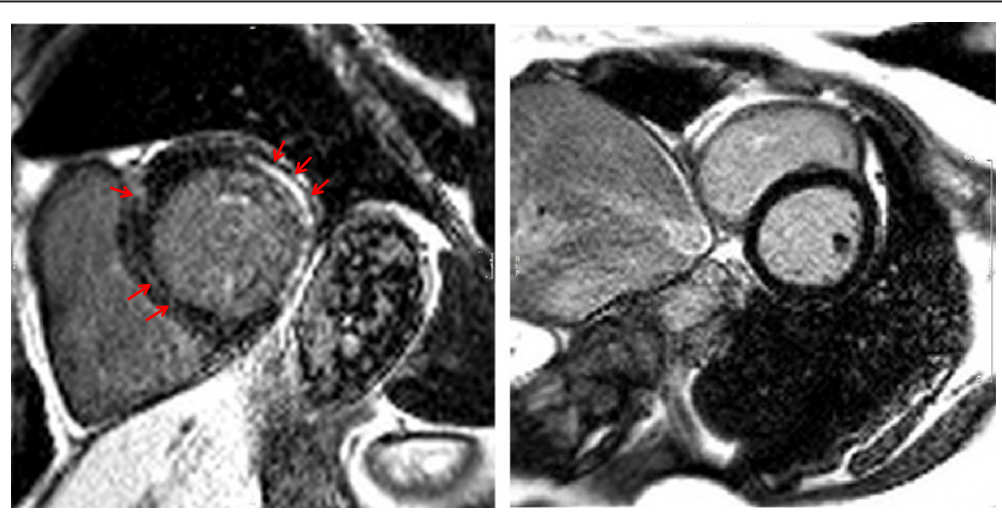

Figure 3 Late gadolinium enhancement. Representative short-axis image (left) showing late gadolinium enhancement of the lateral and posterior left ventricular wall, and of the midwall and posterior hinge point (red arrows) in a 58-year-old man with concomitant AVB grade I. In comparison, normal findings are illustrated on the right. 
Table 2 Gender-specific CMR results in patients with DM1

\begin{tabular}{llll}
\hline & All & Men & Women \\
\hline Myocardial fibrosis, $\mathrm{n}(\%)$ & $12(40)$ & $9(75)$ & $3(25)$ \\
LGE $(\mathrm{g})$, median (range) & $4(1-17)$ & $4(3-17)$ & $3(1-10)$ \\
LVEF $(\%)$, median (range) & $63(38-71)$ & $60(38-65)$ & $66(63-71)$ \\
LVEF $\leq 50 \%, \mathrm{n}(\%)$ & $2(17)$ & $2(22)$ & 0 \\
LVEDV $\left(\mathrm{ml} / \mathrm{m}^{2}\right)$, median (range) & $83(53-130)$ & $89(61-130)$ & $75(53-75)$ \\
LVESV $\left(\mathrm{ml} / \mathrm{m}^{2}\right)$, median (range) & $31(15-73)$ & $33(22-73)$ & $26(15-28)$ \\
LV mass $\left(\mathrm{g} / \mathrm{m}^{2}\right)$, median (range) & $55(43-83)$ & $58(47-83)$ & $44(43-4550)$ \\
LA vol. $\left(\mathrm{ml} / \mathrm{m}^{2}\right)$, median (range) & $52(36-87)$ & $56(46-87)$ & $45(36-49)$ \\
\hline
\end{tabular}

LGE: late gadolinium enhancement.

LV mass: left ventricular mass.

LVEDD: left ventricular end diastolic diameter in diastole.

LVEDV: left ventricular end diastolic volume.

LVEF: left ventricular ejection fraction.

LVESV: left ventricular end systolic volume.

fibrosis seems to have a central role in the pathogenic mechanism in both skeletal and cardiac muscle. In patients with hypertrophic cardiomyopathy, hypertrophy and interstitial fibrosis are important determinants of morbidity and mortality $[39,40]$ and the changes are suggested to occur as a response to trophic and fibrotic factors such as levels of angiotensin II [41]. Transforming growth factor (TGF) $\beta$ is an important mediator of pro-fibrotic signals, and early inhibition of TGF- $\beta$ e.g. with ACE-inhibitors has shown to diminish the development of fibrosis and hypertrophy independent of blood pressure [42]. A recent casereport presented a 50-year-old DM1 patient who suddenly died due to malignant arrhythmia [35]. Autopsy revealed a normal sized heart with no atherosclerotic lesions, but patchy fibrosis involving $20 \%$ of the left and right ventricular myocardium and a strong immune-positive result of TGF- $\beta$ expression. This case was considered by the authors to indicate an association between TGF- $\beta$ and the fibrotic lesions in DM1. In addition, studies have shown that ACE-inhibitors, or ACE-inhibitors in combination with beta-blockers, delay the progression of cardiomyopathy in patients with Duchenne muscular dystrophy (DMD), and has a beneficial effect on long-term survival of DMD patients with heart failure [40,43]. As there are some phenotypic similarities between patients with DM1 and DMD, a similar beneficial pharmacological effect may exist in patients with DM1. Early treatment with ACEinhibitors should therefore be considered and need further investigation in relation to SCD in DM1.

So far, no homogeneous LGE pattern has been described in DM1, which is in accordance with our findings $[18,20]$. However, it seems that mid-myocardial enhancement is most often observed in the septal and basal lateral segments $[18,20]$. Mid-wall fibrosis in patients with nonischaemic dilated cardiomyopathy provides independent prognostic information and improves risk stratification beyond LVEF for all-cause mortality and SCD [44].
Isolated RV-insertion point enhancement was observed in three patients, which can also be observed in healthy individuals, usually as tiny faint enhancement. However, the insertion point fibrosis observed in these patients was prominent and more pronounced than what is seen in healthy individuals. We need to reassess our DM1 patients with CMR, before we can document the prognostic information related not only to the localization but also to the progression of myocardial fibrosis in DM1.

Taken together, myocardial fibrosis may play a central role in the pathogenic process in DM1. Our findings emphasize that CMR add additional information to current screening procedures with a potential major impact on future risk stratification for SCD. Assuming that myocardial fibrosis is a predictor of cardiac outcome, CMR may be a unique tool for identifying high-risk DM1 patients in order to optimize early treatment and prevent SCD.

Longitudinal studies are needed to investigate the prognostic value of myocardial fibrosis and to assess whether improved periodic cardiac assessment, based on the presence, progression and degree of myocardial fibrosis, can prevent life-threatening brady- and tachyarrhythmias through optimized medical treatment and implantation of PMs and ICDs.

\section{Study limitations}

Contrast enhanced CMR is a well-established technique to assess focal myocardial fibrosis. We did not assess the degree of diffuse myocardial fibrosis, hence, we may underestimate and even oversee the fibrotic burden in some patients.

Some patients were not eligible for CMR due to ventilatory assist devices or claustrophobia and few patients refused to participate due to severe muscular impairment. The exclusion of patients with the most severe muscular 
Table 3 Clinical characteristics and CMR-results in patients with and without cardiac fibrosis

\begin{tabular}{llll}
\hline Clinical characteristics & $\begin{array}{l}\text { Fibrosis } \\
\text { (n= 12) }\end{array}$ & $\begin{array}{l}\text { No fibrosis } \\
\text { (n= 18) }\end{array}$ & p-value \\
\hline $\begin{array}{l}\text { Age (years), } \\
\text { mean (SD) }\end{array}$ & $51(18)$ & $44(10)$ & 0.28 \\
$\begin{array}{l}\text { SBP (mmHg), } \\
\text { mean (SD) }\end{array}$ & $128(104-168)$ & $117(97-135)$ & 0.17 \\
$\begin{array}{l}\text { DBP (mmHg), } \\
\text { mean (SD) }\end{array}$ & $78(65-95)$ & $73(56-101)$ & 0.14 \\
$\begin{array}{l}\text { NT-ProBNP (pmol/l), } \\
\text { median (range) }\end{array}$ & $9(1-18)$ & $11(1-41)$ & 0.38 \\
$\begin{array}{l}\text { Myoblobin (ug/l), } \\
\text { median (range) }\end{array}$ & $103(34-162)$ & $69(27-258)$ & 0.56 \\
$\begin{array}{l}\text { CK (U/l), } \\
\text { median (range) }\end{array}$ & $199(56-498)$ & $162(42-780)$ & 0.61 \\
$\begin{array}{l}\text { Handgrip (MRC), } \\
\text { median (range) }\end{array}$ & $3.8(1-5)$ & $4.0(2-5)$ & 0.68 \\
$\begin{array}{l}\text { Ankle dorsal } \\
\text { flexion (MRC), } \\
\text { median (range) }\end{array}$ & $5(1-5)$ & $4.5(3-5)$ & 0.77 \\
& & &
\end{tabular}

\section{CMR-results}

LVEF\%,

median (range)

LGE (g),

median (range)

LVEF $\leq 50 \%$,

$\mathrm{n}(\%)$

$\operatorname{LVEDV~}\left(\mathrm{ml} / \mathrm{m}^{2}\right)$,

median (range)

$\operatorname{LVESV}\left(\mathrm{ml} / \mathrm{m}^{2}\right)$,

median (range)

LV mass $\left(\mathrm{g} / \mathrm{m}^{2}\right)$

median (range)

LA vol. $\left(\mathrm{ml} / \mathrm{m}^{2}\right)$,

median (range)

\section{ECG}

PR interval (ms),

median (range)

QRS interval (ms), median (range)

QTc interval (ms), median (range)

AVB grade I

LBBB

IRBBB

Holter-monitoring

AVB grade II

AF/AFL

SVT

NSVT

$\mathrm{VPC} / \mathrm{h}$, median (range)

$\begin{array}{lll}63(38-71) & 66(60-80) & 0.06 \\ 4(1-17) & 0 & 0.15 \\ 2(17) & 0 & 0.001 \\ 83(53-130) & 71(57-108) & 0.16 \\ 31(15-73) & 25(13-43) & 0.03 \\ 55(43-83) & 46(36-64) & 0.02 \\ 52(36-87) & 46(35-69) & 0.04\end{array}$

$96(70-160) \quad 86(78-120) \quad 0.43$

$411(360-516) \quad 407(346-478) \quad 0.66$

0.69

0.40

0.02

0.25

0.27

0.15

0.40

0.30
$191(160-220) \quad 190(130-260) \quad 0.85$
Table 3 Clinical characteristics and CMR-results in patients with and without cardiac fibrosis (Continued)

\begin{tabular}{|c|c|c|c|}
\hline \multicolumn{4}{|l|}{ Echocardiography } \\
\hline $\begin{array}{l}\text { LVEF (\%), } \\
\text { median (range) }\end{array}$ & $57(45-53)$ & $58(48-67)$ & 0.34 \\
\hline $\begin{array}{l}\text { IVS (mm), } \\
\text { median (range) }\end{array}$ & $8(5-11)$ & $8(6-13)$ & 0.83 \\
\hline $\begin{array}{l}\text { LVEDD (mm), } \\
\text { median (range) }\end{array}$ & $50(40-60)$ & $46(40-60)$ & 0.24 \\
\hline $\begin{array}{l}\text { LVPW (mm), } \\
\text { median (range) }\end{array}$ & $8(5-11)$ & $7(6-12)$ & 0.77 \\
\hline $\begin{array}{l}\text { LV mass ( } \mathrm{g} / \mathrm{m} 2) \text {, } \\
\text { median (range) }\end{array}$ & $74(47-141)$ & $68(46-87)$ & 0.74 \\
\hline $\begin{array}{l}\text { LA vol. }\left(\mathrm{ml} / \mathrm{m}^{2}\right) \text {, } \\
\text { median (range) }\end{array}$ & $26(17-38)$ & $24(14-29)$ & 0.08 \\
\hline $\begin{array}{l}\text { GLS avg. (\%), } \\
\text { median (range) }\end{array}$ & $-19(-14$ to -23$)$ & $-18(-14$ to -25$)$ & 0.75 \\
\hline$E / A$ & $1.2(0.6-2.6)$ & $1.4(0.8-2.4)$ & 0.69 \\
\hline E/E' (lateral) & $5.4(3.5-7.4)$ & $4.9(3.6-8.2)$ & 0.39 \\
\hline MV dec. time (ms) & $150(91-214)$ & 157 (107-239) & 0.81 \\
\hline
\end{tabular}

ACEl: angiotensin converting enzyme inhibitor.

AF/AFL: atrial fibrillation/flutter.

AVB: atrioventricular block.

B-blocker: beta-blocker.

CK: creatine kinase.

DBP: diastolic blood pressure.

GLS: global longitudinal strain.

IRBBB: incomplete right bundle branch block.

IVS: interventricular septum.

LA vol: left atrial volume.

LBBB: left bundle branch block.

LGE: late gadolinium enhancement.

LV mass: left ventricular mass.

LVEDD: left ventricular end diastolic diameter in diastole.

LVEDV: left ventricular end diastolic volume.

LVEF: left ventricular ejection fraction.

LVESV: left ventricular end systolic volume.

LVPW: left ventricular posterior wall.

MRC: medical research council scale.

MV dec. time: mitral valve deceleration time.

NSVT: non-sustained ventricular tachycardia.

SBP: systolic blood pressure.

SVT: supraventricular tachycardia.

VPC/h: ventricular premature contractions/hour.

and respiratory impairment represents selection bias. However, we believe this would be a common bias for all CMR studies in this field. Furthermore, if these patients would have more cardiac involvement than the remaining patients, it would probably skew our results towards substantiating our conclusion that myocardial fibrosis is a frequent finding in patients with DM1.

Several studies have assessed the correlation between CTG repeat length and cardiac involvement with ambiguous results $[3,45]$. A recent study reported a large inter- and intra-tissue CTG length variation in DM1 tissue with the largest expansion in the heart and cerebral cortex [46]. These observations strongly indicate that factors other than genetic are responsible for the observed cardiac involvement in DM1 and explain why 
CTG-repeat length is only estimated for diagnostic purposes.

Due to the relatively small number of patients in our study, the impact of our findings on the clinical management of patients with DM1 is limited and needs to be assessed in larger studies.

\section{Conclusion}

CMR documented a high prevalence of myocardial fibrosis in patients with DM1. Overall, myocardial fibrosis was mainly observed in patients with concomitant abnormal findings on ECG, Holter-monitoring and/or echocardiography. Nevertheless, myocardial fibrosis was also present in $33 \%$ of the patients with normal findings on routine cardiac screening. These findings emphasize that a normal ECG, Holter-monitoring and echocardiography cannot exclude myocardial fibrosis.

CMR adds additional information to the current standard cardiac assessment and might be a valuable tool for risk stratification in DM1. The progression and the prognostic value of myocardial fibrosis needs to be further investigated in longitudinal studies.

\section{Competing interests}

The authors declare that they have no competing interests.

\section{Authors' contributions}

$\mathrm{HP}, \mathrm{HB}$ and LK were responsible for the study design. HP and KAA collected data. HP, JV, HB, KAA and LK contributed to data analysis. All authors contributed to data interpretation and preparation of the manuscript. HP and $\mathrm{HB}$ are responsible for the overall content of the manuscript. All authors read and approved the final manuscript.

\section{Acknowledgements}

\section{Funding}

We thank The Research Foundation of Rigshospitalet, The Danish Heart Foundation, The Lundbeck Foundation and The Stibo Foundation for the financial support. The funders had no influence on the collection, analysis and interpretation of the data; in the writing of the report; and in the decision to submit the paper for publication.

\section{Author details}

'Department of Cardiology, Copenhagen University Hospital, Rigshospitalet, Blegdamsvej 9, 2100 Copenhagen, Denmark. ${ }^{2}$ Neuromuscular Research Unit, Department of Neurology, Copenhagen University Hospital, Rigshospitalet, Copenhagen, Denmark. ${ }^{3}$ Unit for Inherited Cardiac Diseases, Copenhagen University Hospital, Rigshospitalet, Copenhagen, Denmark.

Received: 2 April 2014 Accepted: 18 July 2014

Published online: 01 August 2014

\section{References}

1. Brook JD, MCCurrach ME, Harley HG, Buckler AJ, Church D, Aburatani H, Hunter K, Stanton VP, Thirion JP, Hudson T, et al. Molecular basis of myotonic dystrophy: expansion of a trinucleotide (CTG) repeat at the $3^{\prime}$ end of a transcript encoding a protein kinase family member. Cell. 1992; 68:799-808

2. Groh WJ, Groh MR, Saha C, Kincaid JC, Simmons Z, Ciafaloni E, Pourmand R, Otten RF, Bhakta D, Nair GV, Marashdeh MM, Zipes DP, Pascuzzi RM. Electrocardiographic abnormalities and sudden death in myotonic dystrophy type 1. N Engl J Med. 2008; 358:2688-97.

3. Petri H, Vissing J, Witting N, Bundgaard H, Kober L. Cardiac manifestations of myotonic dystrophy type 1. Int J Cardiol. 2012; 160:82-8.
4. Petri $H$, Witting $N$, Ersboll M, Sajadieh A, Duno M, Helweg-Larsen S, Vissing J, Kober L, Bundgaard $\mathrm{H}$. High prevalence of cardiac involvement in patients with myotonic dystrophy type 1 - a cross-sectional study. Int I Cardiol. in press.

5. Bhakta D, Lowe MR, Groh WJ. Prevalence of structural cardiac abnormalities in patients with myotonic dystrophy type I. Am Heart J. 2004; 147:224-27.

6. Nguyen HH, Wolfe JT III, Holmes DR Jr, Edwards WD. Pathology of the cardiac conduction system in myotonic dystrophy: a study of 12 cases. J Am Coll Cardiol. 1988; 11:662-71.

7. Phillips MF, Harper PS. Cardiac disease in myotonic dystrophy. Cardiovasc Res. 1997; 33:13-22.

8. Church SC. The heart in myotonia atrophica. Arch Intern Med. 1967; 119:176-81.

9. Colleran JA, Hawley RJ, Pinnow EE, Kokkinos PF, Fletcher RD. Value of the electrocardiogram in determining cardiac events and mortality in myotonic dystrophy. Am J Cardiol. 1997; 80:1494-97.

10. Mathieu J, Allard P, Potvin L, Prevost C, Begin P. A 10-year study of mortality in a cohort of patients with myotonic dystrophy. Neurology. 1999; 52:1658-62.

11. Hermans MC, Pinto YM, Merkies IS, de Die-Smulders CE, Crijns HJ, Faber CG. Hereditary muscular dystrophies and the heart. Neuromuscul Disord. 2010; 20:479-92.

12. Warner JP, Barron LH, Goudie D, Kelly K, Dow D, Fitzpatrick DR, Brock DJ. A general method for the detection of large CAG repeat expansions by fluorescent PCR. J Med Genet. 1996; 33:1022-26.

13. Carlsen EA, Bang LE, Ahtarovski KA, Engstrom T, Kober L, Kelbaek H, Vejlstrup N, Jorgensen E, Helqvist S, Saunamaki K, Clemmensen P, Holmvang L, Wagner GS, Lønborg J, Clemmensen P, Holmvang L, Wagner GS, Lønborg J. Comparison of Selvester QRS score with magnetic resonance imaging measured infarct size in patients with ST elevation myocardial infarction. J Electrocardiol. 2012; 45:414-19.

14. Lang RM, Bierig M, Devereux RB, Flachskampf FA, Foster E, Pellikka PA, Picard MH, Roman MJ, Seward J, Shanewise JS, Solomon S, Spencer KT, St John Sutton M, Stewart W. Recommendations for chamber quantification: a report from the American Society of Echocardiography's Guidelines and Standards Committee and the Chamber Quantification Writing Group, developed in conjunction with the European Association of Echocardiography, a branch of the European Society of Cardiology. J Am Soc Echocardiogr. 2005; 18:1440-63.

15. Nagueh SF, Appleton CP, Gillebert TC, Marino PN, Oh JK, Smiseth OA, Waggoner AD, Flachskampf FA, Pellikka PA, Evangelista A.

Recommendations for the evaluation of left ventricular diastolic function by echocardiography. J Am Soc Echocardiogr. 2009; 22:107-33.

16. Yingchoncharoen T, Agarwal S, Popovic ZB, Marwick TH. Normal ranges of left ventricular strain: a meta-analysis. J Am Soc Echocardiogr. 2013; 26:185-91.

17. De AL, Raisaro A, Marchiano V, Radice S, Meola G. Cardiac involvement in patients with myotonic dystrophy: characteristic features of magnetic resonance imaging. Eur Heart J. 1995; 16:1007-10.

18. Hermans MC, Faber CG, Bekkers SC, de Die-Smulders CE, Gerrits MM, Merkies IS, Snoep G, Pinto YM, Schalla S. Structural and functional cardiac changes in myotonic dystrophy type 1: a cardiovascular magnetic resonance study. J Cardiovasc Magn Reson. 2012; 14:48.

19. Nazarian S, Bluemke DA, Wagner KR, Zviman MM, Turkbey E, Caffo BS, Shehata M, Edwards D, Butcher B, Calkins H, Berger RD, Halperin HR, Tomaselli GF. QRS prolongation in myotonic muscular dystrophy and diffuse fibrosis on cardiac magnetic resonance. Magn Reson Med. 2010; 64:107-14.

20. Verhaert D, Richards K, Rafael-Fortney JA, Raman SV. Cardiac involvement in patients with muscular dystrophies: magnetic resonance imaging phenotype and genotypic considerations. Circ Cardiovasc Imaging. 2011; 4:67-76.

21. Turkbey EB, Gai N, Lima JA, van der Geest RJ, Wagner KR, Tomaselli GF, Bluemke DA, Nazarian S. Assessment of cardiac involvement in myotonic muscular dystrophy by $\mathrm{T} 1$ mapping on magnetic resonance imaging. Heart Rhythm. 2012; 9:1691-97.

22. Adabag AS, Maron BJ, Appelbaum E, Harrigan CJ, Buros JL, Gibson CM, Lesser JR, Hanna CA, Udelson JE, Manning WJ, Maron MS. Occurrence and frequency of arrhythmias in hypertrophic cardiomyopathy in relation to delayed enhancement on cardiovascular magnetic resonance. J Am Coll Cardiol. 2008; 51:1369-74. 
23. Segawa I, Suzuki T, Kato M, Tashiro A, Satodate R. Relation between myocardial histological changes and ventricular tachycardia in cardiomyopathy: a study by 24-hour ECG-monitoring and endomyocardial biopsy. Heart Vessels Suppl. 1990; 5:37-40.

24. Strain JE, Grose RM, Factor SM, Fisher JD. Results of endomyocardial biopsy in patients with spontaneous ventricular tachycardia but without apparent structural heart disease. Circulation. 1983; 68:1171-81.

25. Teraoka K, Hirano M, Ookubo H, Sasaki K, Katsuyama H, Amino M, Abe Y, Yamashina A. Delayed contrast enhancement of MRI in hypertrophic cardiomyopathy. Magn Reson Imaging. 2004; 22:155-61.

26. Nazarian S, Bluemke DA, Lardo AC, Zviman MM, Watkins SP, Dickfeld TL, Meininger GR, Roguin A, Calkins H, Tomaselli GF, Weiss RG, Berger RD, Lima $J A$, Halperin HR. Magnetic resonance assessment of the substrate for inducible ventricular tachycardia in nonischemic cardiomyopathy. Circulation. 2005; 112:2821-25.

27. Bello D, Fieno DS, Kim RJ, Pereles FS, Passman R, Song G, Kadish AH, Goldberger JJ. Infarct morphology identifies patients with substrate for sustained ventricular tachycardia. J Am Coll Cardiol. 2005; 45:1104-08.

28. Kwong RY, Chan AK, Brown KA, Chan CW, Reynolds HG, Tsang S, Davis RB. Impact of unrecognized myocardial scar detected by cardiac magnetic resonance imaging on event-free survival in patients presenting with signs or symptoms of coronary artery disease. Circulation. 2006; 113:2733-43.

29. Shiozaki AA, Senra T, Arteaga E, Martinelli FM, Pita CG, Avila LF, Parga Filho JR, Mady C, Kalil-Filho R, Bluemke DA, Rochitte CE. Myocardial fibrosis detected by cardiac CT predicts ventricular fibrillation/ventricular tachycardia events in patients with hypertrophic cardiomyopathy. J Cardiovasc Comput Tomogr. 2013; 7:173-81.

30. Yan AT, Shayne AJ, Brown KA, Gupta SN, Chan CW, Luu TM, Di Carli MF, Reynolds HG, Stevenson WG, Kwong RY. Characterization of the peri-infarct zone by contrast-enhanced cardiac magnetic resonance imaging is a powerful predictor of post-myocardial infarction mortality. Circulation. 2006; 114:32-9.

31. Pelargonio G, Dello RA, Sanna T, De MG, Bellocci F. Myotonic dystrophy and the heart. Heart. 2002; 88:665-70.

32. Bharati S, Bump FT, Bauernfeind R, Lev M. Dystrophica myotonia. Correlative electrocardiographic, electrophysiologic, and conduction system study. Chest. 1984; 86:444-50.

33. Motta J, Guilleminault C, Billingham M, Barry W, Mason J. Cardiac abnormalities in myotonic dystrophy. Electrophysiologic and histopathologic studies. Am J Med. 1979; 67:467-73.

34. Wang GS, Kearney DL, De BM, Taffet G, Cooper TA. Elevation of RNA-binding protein CUGBP1 is an early event in an inducible heart-specific mouse model of myotonic dystrophy. J Clin Invest. 2007; 117:2802-11.

35. Turillazzi E, Neri M, Riezzo I, Di PM, Evangelisti L, Fineschi V. Cardiac fibrosis, arrhythmia and sudden death in myotonic dystrophy type 1: Could TGF-ss1 improve the predictive accuracy of patients at risk, opening new therapeutic challenges? Int J Cardiol. 2013; 168:4976-78.

36. Meola G, Cardani R. Myotonic dystrophies: an update on clinical aspects, genetic, pathology, and molecular pathomechanisms. Biochim Biophys Acta. 2014; pii: S0925-4439(14)00147-1. doi:10.1016/j.bbadis.2014.05.019. [Epub ahead of print].

37. Kimura $T$, Nakamori M, Lueck JD, Pouliquin P, Aoike F, Fujimura H, Dirksen RT, Takahashi MP, Dulhunty AF, Sakoda S. Altered mRNA splicing of the skeletal muscle ryanodine receptor and sarcoplasmic/endoplasmic reticulum $\mathrm{Ca} 2+-$ ATPase in myotonic dystrophy type 1 . Hum Mol Genet. 2005; 14:2189-200.

38. Tang ZZ, Yarotskyy V, Wei L, Sobczak K, Nakamori M, Eichinger K, Moxley RT, Dirksen RT, Thornton CA. Muscle weakness in myotonic dystrophy associated with misregulated splicing and altered gating of $\mathrm{Ca}(\mathrm{V}) 1.1$ calcium channel. Hum Mol Genet. 2012; 21:1312-24.

39. Elliott PM, Gimeno Blanes JR, Mahon NG, Poloniecki JD, McKenna WJ. Relation between severity of left-ventricular hypertrophy and prognosis in patients with hypertrophic cardiomyopathy. Lancet. 2001; 357:420-24.

40. Green JJ, Berger JS, Kramer CM, Salerno M. Prognostic value of late gadolinium enhancement in clinical outcomes for hypertrophic cardiomyopathy. JACC CardiovasC Imaging. 2012; 5:370-77.

41. Marian AJ. Pathogenesis of diverse clinical and pathological phenotypes in hypertrophic cardiomyopathy. Lancet. 2000; 355:58-60.

42. Teekakirikul $P$, Eminaga $S$, Toka O, Alcalai R, Wang L, Wakimoto H, Nayor M Konno T, Gorham JM, Wolf CM, Kim JB, Schmitt JP, Molkentin JD, Norris RA,
Tager AM, Hoffman SR, Markwald RR, Seidman CE, Seidman JG. Cardiac fibrosis in mice with hypertrophic cardiomyopathy is mediated by non-myocyte proliferation and requires Tgf-beta. J Clin Invest. 2010; 120:3520-29.

43. Ogata H, Ishikawa Y, Ishikawa Y, Minami R. Beneficial effects of betablockers and angiotensin-converting enzyme inhibitors in Duchenne muscular dystrophy. J Cardiol. 2009; 53:72-8.

44. Gulati A, Jabbour A, Ismail TF, Guha K, Khwaja J, Raza S, Morarji K, Brown TD, Ismail NA, Dweck MR, Di Pietro E, Roughton M, Wage R, Daryani Y, O'Hanlon R, Sheppard MN, Alpendurada F, Lyon AR, Cook SA, Cowie MR, Assomull RG, Pennell DJ, Prasad SK. Association of fibrosis with mortality and sudden cardiac death in patients with nonischemic dilated cardiomyopathy. JAMA. 2013; 309:896-908.

45. Sansone VA, Brigonzi E, Schoser B, Villani S, Gaeta M, De AG, Bandera F, De $A L$, Meola $G$. The frequency and severity of cardiac involvement in myotonic dystrophy type 2 (DM2): Long-term outcomes. Int J Cardiol. 2012; 168:1147-53.

46. Lopez CA, Nakamori M, Tome S, Chitayat D, Gourdon G, Thornton CA, Pearson CE. Expanded CTG repeat demarcates a boundary for abnormal $\mathrm{CpG}$ methylation in myotonic dystrophy patient tissues. Hum Mol Genet. 2011; 20:1-15.

\section{doi:10.1186/s12968-014-0059-z}

Cite this article as: Petri et al:: Myocardial fibrosis in patients with myotonic dystrophy type 1: a cardiovascular magnetic resonance study. Journal of Cardiovascular Magnetic Resonance 2014 16:59.

\section{Submit your next manuscript to BioMed Central and take full advantage of:}

- Convenient online submission

- Thorough peer review

- No space constraints or color figure charges

- Immediate publication on acceptance

- Inclusion in PubMed, CAS, Scopus and Google Scholar

- Research which is freely available for redistribution 